\title{
La Potencialidad Turística En Los Proyectos De Turismo Rural Comunitario
}

\author{
Gabriela Estefanía Román Santamaría \\ Mónica Cecilia Zurita Vintimilla \\ Gabriela Natalí Fonseca Romero \\ Danny Daniel Castillo Vizuete \\ Luis Alberto Quevedo Báez
}

Docentes - Investigadores - Escuela Superior Politécnica de

Chimborazo, Riobamba, Ecuador

doi: 10.19044/esj.2017.v13n20p219 URL:http://dx.doi.org/10.19044/esj.2017.v13n20p219

\begin{abstract}
Tourism is one of the main productive sectors that allow the improvement of the economy in diverse territories. The community of Guasuntos is regarded as a territory with natural and cultural scenic importance. The same, however, can be used in the development of tourism projects with the challenge of turning it into a competitive tourist destination. This was an alternative for local development in generating wealth in favor of the population, fostering the systemic competitiveness of the territory, and generating a guiding process that coordinates public, private, and community efforts. In order to involve the community in the development of this productive activity, an analysis of the situational diagnosis was carried out. Here, information was collected on the biophysical, sociocultural, economic productive components, political human settlement, mobility, energy, and institutional connectivity. In the territory, the inventory of natural and cultural attractions was carried out. This was done using the methodology proposed by the Ministry of Tourism (MINTUR). Finally, the characterization of the tourist demand was carried out. The tourist demand helps to identify the potential market with the consumption capacity of the product. The evaluation of the tourist potential in the territories allows for the identification of the vocation. However, this became a starting tool for the formulation of projects and a planning tool that contributes to the conservation of resources and the implementation of any activity. In addition, it ensures a potential and orderly use of them and serves as a developmental support for the population.
\end{abstract}


Keywords: Planning, evaluation, components, local tourism

\section{Resumen}

El turismo es uno de los principales sectores productivos que permite mejorar la economía en diversos territorios, la comunidad de Guasuntos se muestra como un territorio con importancia escénica natural y cultural, la misma que puede ser aprovechada en el desarrollo de proyectos turísticos con el reto de convertir al mismo en un destino turístico competitivo, como una alternativa de desarrollo local en la generación de riquezas a favor de la población, fomentando la competitividad sistémica del territorio y generando un proceso orientador que coordine esfuerzos públicos, privados y comunitarios. Para que la comunidad se inserte en el desarrollo de esta actividad productiva se realizó un análisis del diagnóstico situacional en el cual se recabo información de los componentes biofísico, sociocultural, económico productivo, asentamientos humanos político y movilidad, energía y conectividad institucional que actúan en el territorio, se realizó el inventario de atractivos naturales y culturales, con la metodología propuesta por el Ministerio de Turismo (MINTUR) y finalmente se realizó la caracterización de la demanda turística lo que permitió identificar el mercado potencial con capacidad de consumo del producto. La evaluación del potencial turístico en los territorios permite identificar la vocación del mismo, lo que se convierte en una herramienta de partida para la formulación de proyectos y un instrumento de planificación que aporta a la conservación de los recursos y la puesta en marcha de cualquier actividad que asegure un uso potencial y ordenado de los mismos, sirviendo como un soporte de desarrollo para la población.

Palabras claves: planificación, evaluación, componentes, turismo local

\section{Introducción}

Debido en gran parte al proceso de democratización del tiempo y del espacio y al desarrollo del soporte infraestructural, el Turismo se ha constituido en un segmento fundamental del ocio, entendiendo el ocio como la porción de tiempo libre que se emplea en determinadas actividades $\mathrm{u}$ ocupaciones para descansar, recrearse, informarse y formarse (Gil, 2003). El Turismo establece un sistema que abarca un proceso de interacción donde participan múltiples actores, como lo manifiesta CODESPA, entre ellos las comunidades y diferentes entes públicos (organismos reguladores de la actividad turística) y privados (agencias de turismo), además de los lugares considerados espacios cargados de significados y simbolizaciones (Meethan, 2001). Uno de los principales componentes que forman parte de esta actividad es la oferta que permite que el turismo se desarrolle de forma 
efectiva, la cual se enfoca en la generación de rentabilidad económica, social y ambiental al ofrecer aquello que buscan los consumidores (Benayas, 1994), quienes se caracterizan por su creciente capacidad de elección en los aspectos motivacionales, temporales y territoriales (Bercial \& Timón, 2005); sin olvidar la existencia de intereses individuales y colectivos, donde nadie puede aumentar su bienestar sin disminuir el del otro. De este modo, Monreal (2002) indica que el turismo no debe ser percibido en sí mismo como una solución a los problemas del subdesarrollo, ni como la fuerza destructiva que ineludiblemente arrasa con la diversidad y la identidad de los pueblos, sino más bien como una alternativa de desarrollo local, es decir, una actividad necesariamente compatible con el medio ambiente y con el medio social en el que se inserta la comunidad, enfocándose en un modelo de gestión de los recursos desde la perspectiva de protección y conservación de los recursos para el aprovechamiento de futuras generaciones llevando a cabo un modelo de planificación.

En Ecuador, el turismo es catalogado como una actividad económica prioritaria, declarada política de estado por ser uno de los sectores con mayor dinamismo (Senplades, 2013). Esta actividad ocupa el cuarto lugar en el sector productivo, contribuyendo al incremento del producto interno bruto (PIB) del país luego de la construcción, agricultura, pesca y la industria manufacturera, y ha sido tomada como eje fundamental para el cambio de la matriz productiva mediante la diversificación de ingresos no petroleros (MCPEYC, 2014).

Por ello resulta necesario desarrollar políticas que garanticen la protección de los recursos naturales y culturales que sustentan la actividad para la satisfacción de las necesidades de los turistas y las poblaciones residentes presentes y futuras (Sharpley, 2000). Hoy en día el turismo comunitario, representa una gran oportunidad de desarrollo para las comunidades, dado que la presencia de elementos naturales y culturales distintivos permite la creación y gestión de productos turísticos innovadores que pueden complementar la oferta existente y determinar una mayor inclusión en los beneficios de la actividad turística (CODESPA, 2011), permite además dinamizar las actividades económicas tradicionales y valorizar las particularidades naturales y culturales locales (Blanco, 2008), así el turismo comunitario no sólo se proyecta desde el enfoque de rentabilidad económica, sino como elemento de bienestar y de desarrollo integral del país (Burgos \& Cardona, 2014), siempre en la búsqueda constante de mejorar la calidad de vida de la población y su bienestar.

En efecto, las actividades turísticas se desarrollan en aquellos lugares que cuentan con atractivos, los cuales pueden ser elementos naturales e hitos de interés cultural (Aspas, 2000) y están incluidos dentro del sistema de producción y consumo turístico, constituyéndose en elementos principales 
para la elaboración de productos y la diversificación de la oferta (Bercial \& Timón, 2005). Por ello, tiene lógica hablar de nuevos destinos y formas de concebir un turismo más enfocado a satisfacer las necesidades de esparcimiento y búsqueda de sensaciones de los turistas a través de la creación de nuevos productos turísticos que incorporen conocimientos, valores, actividades recreativas, insumos y destrezas tradicionales de las comunidades participantes, dependiendo de la vocación de los territorios, identificando las características y condiciones para que un destino sea interesante (vocación dada por la potencialidad turística de los territorios), lo cual busca consolidar un sistema turístico fortalecido desde la faceta del modelo oferta - demanda que permita generar productos turísticos (Boullón, 1997) que actúen a mediano plazo como un factor de desarrollo (De Blas, et al., 2004) enfocado en la oferta integrada por atracciones y actividades expresadas en el conjunto de lugares, bienes, costumbres y acontecimientos, que por sus características propias o de ubicación, atraen el interés del visitante (Carrasquero, 2004); en la infraestructura representada por las construcciones subterráneas y de superficie como elementos básicos para el desarrollo del turismo (Valencia, 2012); en la planta turística dada por la estructura productiva del turismo por ser el medio para brindar los servicios de permanencia, desplazamiento y aprovechamiento de los atractivos y actividades (Castro, 2010) y en la superestructura que comprende todos los organismos especializados tanto públicos como privados encargados de optimizar y modificar cuando sea necesario el funcionamiento de cada una de las partes que integran el sistema así como armonizar sus relaciones para facilitar la producción y venta de los servicios que componen el producto turístico (Jiménez, 1986).

Por otro lado, la demanda ha sido definida como la cuantificación de la necesidad real o psicológica de una población de compradores, con poder adquisitivo suficiente para obtener un determinado producto que satisfaga dicha necesidad (Acevedo et al., 2010). De manera complementaria, Blanco (2008) señala que la única manera de confirmar que un territorio posee verdaderamente un potencial de desarrollo turístico que justifique determinadas inversiones es a través de una evaluación rigurosa que tenga en cuenta los atractivos del territorio, la oferta, la demanda y las tendencias del mercado.

Por consiguiente, resulta necesaria la evaluación del potencial turístico de los territorios, con el fin de identificar las oportunidades y fortalezas que promuevan una oferta turística, en la que se evidencien los atractivos naturales y culturales, considerados elementales para distinguir al destino (Santana, 2003). Es esto un punto de partida para la formulación de proyectos turísticos de calidad basados en una nueva forma de organizar los servicios en la cual prime, ante todo, la satisfacción del cliente y la 
adecuación de lo ofrecido a sus necesidades y expectativas, con el objetivo de obtener y mantener una posición competitiva en el mercado y fidelizar a los clientes, a través de brindarles la posibilidad de atesorar vivencias únicas en lo festivo, lo lúdico, lo natural y cultural (Bercial \& Timón, 2005). Desde esta perspectiva, más que una actividad económica, el turismo podría ser catalogado como un intercambio cultural entre sociedades, que precisa situarse en un territorio, que utiliza sus características y recursos, que implica actividades económicas y que puede llegar a reconfigurar y reordenar ese territorio.

El objetivo de esta investigación fue desarrollar la evaluación del potencial turístico en la parroquia rural Guasuntos perteneciente al cantón Alausí, lo cual se logró a través de la elaboración del diagnóstico situacional, de la elaboración del inventario de los atractivos naturales y culturales y de la caracterización de la demanda.

\section{Localización}

La presente investigación se la realizó en la parroquia Guasuntos (mapa 1) ubicada en el cantón Alausí de la provincia de Chimborazo.

Mapa 1. Ubicación geográfica de la parroquia Guasuntos.

\section{MAPA DE UBICACIÓN GEOGR ÁFICA DE LA PARROQUIA GUASUNTOS}

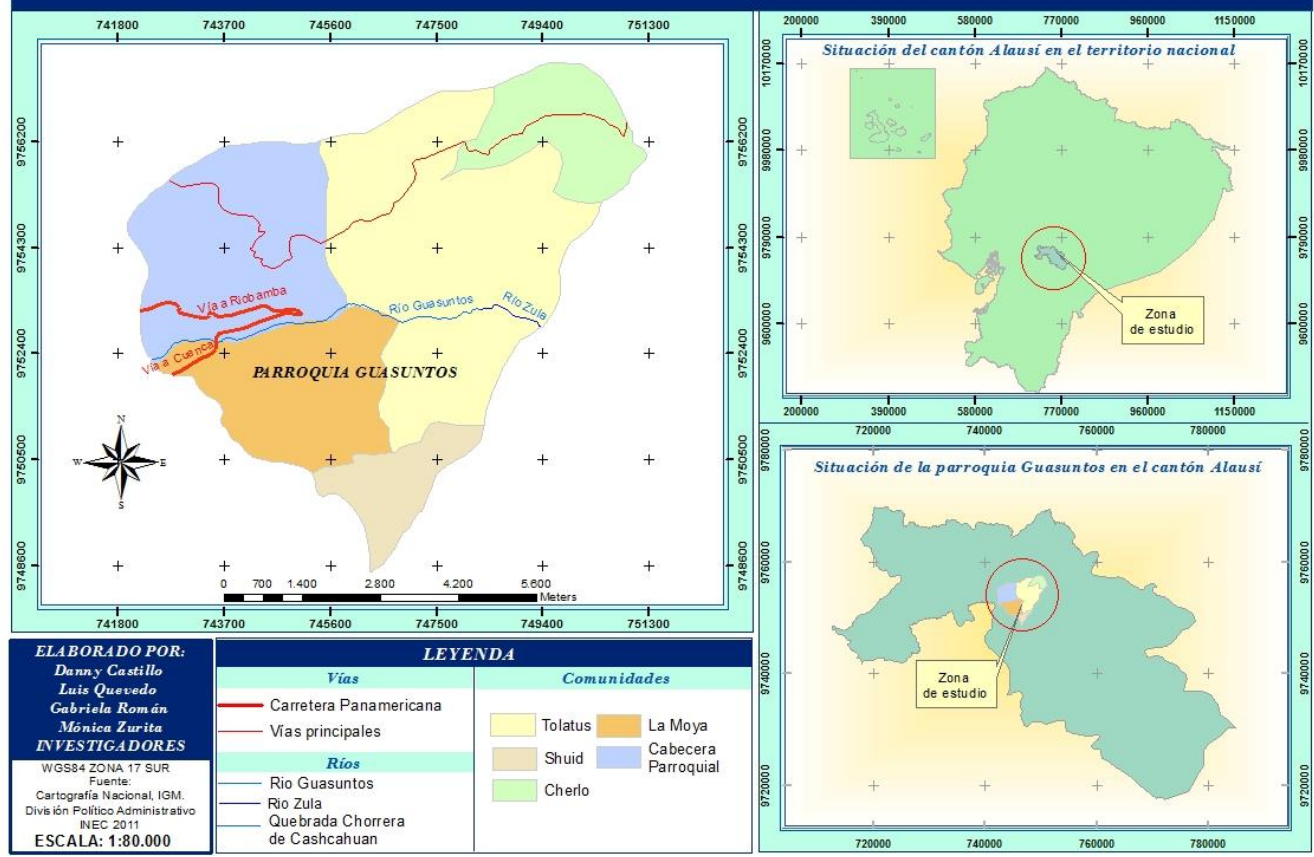

Elaborado por: equipo de investigación 


\section{Metodología}

La investigación se desarrolló inicialmente a partir del análisis del diagnóstico situacional el cual se recabo información de los componentes que actúan en el territorio: biofísico, sociocultural, económico productivo, asentamientos humanos, movilidad, energía y conectividad y político institucional, los cuales permitieron conocer la realidad actual del territorio utilizando métodos de levantamiento de información primaria con las siguientes técnicas: talleres con grupos focales, observación de campo y entrevistas e información secundaria (documental) en fuentes oficiales del Sistema Nacional de Información y el Plan de Desarrollo y Ordenamiento Territorial de la parroquia Guasuntos, 2015.

Posteriormente, se procedió a elaborar el inventario de atractivos naturales y culturales, realizado a partir de salidas de campo y talleres participativos con los dirigentes comunales y la población local como informantes directos de la realidad territorial. De esta manera, se aplicó la metodología propuesta por el MINTUR, 2004 (Ministerio de Turismo del Ecuador) siendo sus etapas: clasificación de los atractivos, recopilación de información, trabajo de campo, evaluación y jerarquización. En el caso del patrimonio cultural inmaterial se utilizó la metodología propuesta por el Instituto Nacional de Patrimonio Cultural INPC (2011), siendo sus etapas: observación directa, entrevistas a pobladores locales, registros, diagnóstico e inventario y sistematización de la información.

Se realizó la caracterización de la demanda turística en la cual se determinó el universo de estudio que estuvo conformado por el número total de turistas nacionales (40248) y extranjeros (53352) que visitaron el cantón Alausí, haciendo uso de la Ruta Férrea Alausí - Nariz del Diablo, que corresponde a 93600 turistas al año datos proporcionados por la Empresa Ferrocarriles del Ecuador (2014); luego se estableció la muestra, la misma que fue calculada con un error de $8 \%$ y con un valor de confianza igual a 2 , con una probabilidad de ocurrencia y no ocurrencia de 0.5 , dando como resultado 156 personas a ser entrevistadas, con una distribución de 67 encuestas para turistas nacionales y 89 encuestas para turistas extranjeros en función a los estratos que forman parte de la población en estudio.

Finalmente, a partir de la elaboración del inventario de atractivos naturales y culturales y la caracterización de la demanda turística, se desarrollaron talleres participativos con la comunidad en los cuales se identificó una posibilidad de diseñar un producto turístico para desarrollar en la zona. 


\section{Resultados y Discusión}

El diagnóstico territorial es la primera fase para la organización espacial, Salinas y Quintela (2001) mencionan que para el levantamiento del diagnóstico es importante determinar indicadores: ambientales, sociales, económicos y legales/institucionales, sin embargo, el Ecuador responde a un modelo de desarrollo basado en los planes de ordenamiento territorial, instrumento de planificación fundamentado en el Código Orgánico de Organización Territorial, Autonomía y Descentralización (COOTAD), el cual es el cuerpo legal que permite organizar el territorio, basando su diagnóstico a partir de los componentes: biofísico, sociocultural, económico, asentamientos humanos, movilidad, energía, conectividad, político institucional y de participación. En la Tabla 1 se puede observar el levantamiento del diagnóstico en la parroquia Guasuntos a partir de estos componentes.

Tabla 1. Diagnóstico situacional de la parroquia Guasuntos en base a los componentes (biofísico, sociocultural, económico productivo, asentamientos humanos, movilidad, energía y conectividad, y político institucional).

\begin{tabular}{|c|c|}
\hline \multicolumn{2}{|r|}{ PARROQUIA GUASUNTOS } \\
\hline COMPONENTES & DESCRIPCIÓN \\
\hline BIOFÍSICO & $\begin{array}{l}\text { Rango altitudinal: } 2400 \text { - } 3720 \text { m.s.n.m. } \\
\text { Suelos: irregulares y con pendientes elevadas de tipo montañoso en un } \\
68.7 \% \text {. } \\
\text { Textura: tipo arenoso en un } 95.4 \% \text {. } \\
\text { Uso y cobertura del suelo: el } 78 \% \text { por cultivos de ciclo corto: coles, papas, } \\
\text { acelga, cebolla blanca, zanahoria, rábano, maíz, cebada y trigo; el } 17 \% \\
\text { pasto natural y el } 5 \% \text { áreas cubiertas de páramo. } \\
\text { Pisos climáticos: Ecuador de Alta Montaña y Ecuador Mesotérmico Seco. } \\
\text { Temperatura: } 6-14{ }^{\circ} \mathrm{C} \text {. } \\
\text { Precipitación: } 0-750 \mathrm{~mm} \text { anual. } \\
\text { Humedad relativa: } 50 \text { y } 80 \% \text {. } \\
\text { Clasificación ecológica: arbustal siempre verde montano del norte de los } \\
\text { Andes. }\end{array}$ \\
\hline SOCIOCULTURAL & $\begin{array}{l}\text { Ubicación: cantón Alausí, provincia de Chimborazo. } \\
\text { Fecha de creación: } 12 \text { de Mayo de } 1971 \text {. } \\
\text { Habitantes: } 1152 \text { hombres y } 1352 \text { mujeres. } \\
\text { Población por comunidades: cabecera parroquial } 456 \text { ha, Tolatus } 264 \text { ha, } \\
\text { Cherlo } 175 \text { ha, Shuid } 1278 \text { ha y La Moya } 331 \text { ha. } \\
\text { Número de familias por comunidades: cabecera parroquial 147, Tolatus } \\
75 \text {, Cherlo } 62 \text {, Shuid } 310 \text { y La Moya } 136 \text {. } \\
\text { Clasificación poblacional: } 550 \text { infantes, } 802 \text { jóvenes, } 730 \text { adultos y } 422 \\
\text { adultos mayores. } \\
\text { Educación: la tasa de asistencia por nivel de educación es básica } 33 \% \text {, } \\
\text { primaria } 32 \% \text {, secundaria } 16 \% \text {, bachillerato } 16 \% \text { y superior } 3 \% \text {. } \\
\text { Salud: dos centros de salud con servicios de vacunación, ginecología, } \\
\text { medicina general, odontología y un área de farmacia. }\end{array}$ \\
\hline $\begin{array}{l}\text { ECONÓMICO } \\
\text { PRODUCTIVO }\end{array}$ & $\begin{array}{l}\text { Población Económicamente Activa: } 1080 \text { personas. } \\
\text { Superficie productiva: } 1160 \text { ha, con un promedio de tenencia de la tierra de }\end{array}$ \\
\hline
\end{tabular}




\begin{tabular}{|c|c|}
\hline & $\begin{array}{l}0.90 \text { ha; de ello el } 88 \% \text { que corresponde a } 1019 \text { ha se encuentran legalizadas. } \\
\text { La disponibilidad de riego es } 764 \text { ha. } \\
\text { En las comunidades de Tolatus, Shuid, Cherlo y La Moya la población posee } \\
\text { pequeños huertos familiares para autoconsumo. } \\
\text { Se siembra: papa, cebada, trigo, maíz, fréjol, habas, frutales y hortalizas. }\end{array}$ \\
\hline $\begin{array}{c}\text { ASENTAMIENTOS } \\
\text { HUMANOS }\end{array}$ & $\begin{array}{l}\text { Extensión territorial: } 4573.67 \mathrm{Ha} \text {. } \\
\text { Límites parroquiales: al norte parroquia Tixán, al sur parroquia Pumallacta } \\
\text { y Achupallas, al este parroquia Achupallas y al oeste parroquia Matriz y } \\
\text { Alausí. } \\
\text { División parroquial: cabecera parroquial, Tolatus, Cherlo, La Moya y } \\
\text { Shuid. } \\
\text { Agua potable: cobertura con red pública } 419 \text { familias, pozo } 54 \text { familias, rio } \\
\text { o vertiente } 236 \text { familias y lluvia o tanque } 21 \text { familias. } \\
\text { Alcantarillado: cobertura con alcantarillado } 262 \text { familias, pozo séptico } 84 \\
\text { familias y a campo abierto } 384 \text { familias. }\end{array}$ \\
\hline $\begin{array}{c}\text { MOVILIDAD, } \\
\text { ENERGÍAY } \\
\text { CONECTIVIDAD }\end{array}$ & $\begin{array}{l}\text { Vías: cabecera parroquial - Cherlo } 13.8 \mathrm{~km} \text { estado lastrado, cabecera } \\
\text { parroquial - Tolatus } 10.5 \mathrm{~km} \text { estado lastrado, cabecera parroquial - Shuid } \\
11.5 \mathrm{~km} \text { asfaltado }-2.3 \mathrm{~km} \text { lastrado y cabecera parroquial - La Moya } 4 \mathrm{~km} \\
\text { estado asfaltado. } \\
\text { Transporte: Cooperativa "San Luis de Guasuntos" transporte intercantonal } \\
\text { compuesta por camionetas y camiones de carga liviana, cuenta con } 20 \\
\text { unidades. La cooperativa Alausí con las la ruta Alausí - Cuenca en horarios } \\
\text { de } 06: 00 \text { am - 10:00 am. Las cooperativas que cruzan la parroquia son: la } \\
\text { cooperativa Patria, Chunchi, Sucre y Santa. Las comunidades de Shuid, } \\
\text { Tolatus y Cherlo no poseen cobertura de transporte deseable para atender las } \\
\text { necesidades. } \\
\text { Energía eléctrica: servicio brindado por la Empresa Eléctrica Riobamba } \\
\text { S.A, cubriendo un } 84.31 \% \text { del territorio. } \\
\text { Telefonía: La Moya y la cabecera parroquial cuentan con telefonía fija. Las } \\
5 \text { comunidades cuentan con telefonía móvil con señal irregular con redes } \\
\text { móviles de Movistar, Claro y CNT. }\end{array}$ \\
\hline $\begin{array}{c}\text { POLÍTICO } \\
\text { INSTITUCIONAL }\end{array}$ & $\begin{array}{l}\text { Funciones que desempeñan las autoridades: } \\
\text { Presidente: representación legal, ejercer la facultad ejecutiva del gobierno } \\
\text { parroquial. } \\
\text { Vocales: intervenir en las sesiones, presentar proyectos, acuerdos, } \\
\text { resoluciones, intervenir en asambleas y comisiones, fiscalizar y cumplir las } \\
\text { funciones encomendadas por el gobierno parroquial. } \\
\text { Secretaria / tesorera: ocuparse de la secretaría general y ser responsable del } \\
\text { manejo contable. } \\
\text { Técnico de planificación: responsable de la planificación y ejecución de } \\
\text { proyectos. }\end{array}$ \\
\hline
\end{tabular}

Fuente: PD y OT Guasuntos, 2015.

El turismo está integrado por la oferta la cual se desarrolla a partir de variables que son: atractivos y actividades, infraestructura, planta turística y superestructuras. En este estudio, el diagnóstico permitió identificar características en base a la oferta actual del territorio, se identificó que la comunidad no ha logrado disponer de infraestructura básica de calidad en el sistema de agua potable, en donde la cobertura de red pública abastece a 419 
familias, 54 familias cuentan con pozos, 236 familias hacen uso de agua del rio o vertiente y 21 familias de agua lluvia o tanque; en el sistema de alcantarillado, en donde la cobertura abastece a 262 familias, 84 familias utilizan pozo séptico y 384 familias realizan sus necesidades biológicas en campo abierto; en el sistema vial es lastrado en las vías de la cabecera parroquial a Cherlo $13.8 \mathrm{~km}$ a Tolatus $10.5 \mathrm{~km}$ y a Shuid. Con respecto al sistema de energía eléctrica cubre un $84.31 \%$ del territorio, para la generación de productos, es importante contar con infraestructura básica para la prestación de servicios y actividades, esto es competencia de los Gobiernos Autónomos Descentralizados, en este caso parroquial fundamentado en la normativa generada por el COOTAD enfocada en:

- Definir estrategias participativas de apoyo a la producción.

- Fortalecimiento de las cadenas productivas con un enfoque de equidad.

- Servicios técnicos y financieros a la producción.

- Transferencia de tecnología, desarrollo del conocimiento y preservación de los saberes ancestrales.

- Agregación de valor para lo cual se promoverá la investigación científica y tecnológica.

- Dotar de infraestructura de apoyo a la producción.

- Motivar a organizaciones económicas de los productores.

- Emprendimientos económicos y empresas comunitarias, redes de comercialización.

- Participación ciudadana en el control de las estrategias productivas.

- Programas y proyectos orientados al incremento de la productividad, optimización del riego, asistencia técnica, suministro de insumos agropecuarios y transferencia de tecnología, dirigidos principalmente a los micro y pequeños productores.

- Acceso equitativo a los factores de producción.

En la parroquia Guasuntos, con la finalidad de fortalecer el desarrollo turístico se han inventariado los atractivos naturales y culturales (Tabla 4) y se realizó ademas el análisis del mercado turístico.

Pérez y Crispín (2005) con base en el método de jerarquización de la Organización de los Estados Americanos, y a partir de las modificaciones a éste, hechas por Álvarez y Leno (1986), en donde establecen dentro de una escala ordinal y en base a la variable del índice de potencial turístico natural (Tabla 2), identifican cinco jerarquías de recursos:

- Jerarquía 1: recursos con poco o nulo interés

- Jerarquía 2: interés local

- Jerarquía 3: interés regional

- Jerarquía 4: interés nacional

- Jerarquía 5: interés internacional 
Tabla 2. Variables utilizadas en el índice de potencialidad turístico natural

\begin{tabular}{|c|l|}
\hline Naturales & Unidades geomorfológicos \\
& Asociaciones vegetales \\
& Elementos naturales distintivos \\
\hline \multirow{3}{*}{ Accesibilidad } & Transporte terrestre, marítimo y aéreo \\
& Gasolineras \\
& Densidad vial \\
\hline \multirow{4}{*}{ Equipamiento } & Hoteles \\
& Establecimientos de alimentos y bebidas \\
& Unidades de promoción turística \\
& Bancos \\
& Establecimientos comerciales \\
\hline
\end{tabular}

Fuente: INEGI 2002; SECTUR, 2002. (Pérez \& Crispín, 2005).

Por su parte, el Ministerio de Turismo de Ecuador plantea una ficha para inventariar y jerarquizar para los atractivos naturales, la cual permite identificar diferentes variables para jerarquizar el atractivo (Tabla 3)

- Jerarquía 1: atractivos sin méritos suficientes, de interés local.

- Jerarquía 2: atractivos con un rasgo llamativo, de interés regional.

- Jerarquía 3: atractivos capaces de atraer una corriente de mercado nacional.

- Jerarquía 4: atractivos excepcionales capaces de atraer una corriente de mercado internacional.

Tabla 3. Variables de jerarquización

\begin{tabular}{|c|l|}
\hline & Encuestador \\
& Supervisor evaluador \\
& Categoría \\
& Tipo \\
& Subtipo \\
& Ubicación \\
& Centros urbanos más cercanos al atractivo \\
\hline Calidad & Valor intrínseco \\
& Valor extrínseco \\
& Estado de conservación del atractivo \\
& Estado de conservación del entorno \\
\hline \multirow{2}{*}{ Apoyo } & Infraestructura vial y de acceso \\
& Infraestructura básica \\
& Asociación con otros atractivos \\
& Difusión del atractivo \\
\hline
\end{tabular}

Fuente: MINTUR 2009

Mientras que Pérez y Crispín (2005) desarrollan una escala de 5 jerarquías y mencionan que la jerarquía 1 es de interés nulo, el Ministerio de Turismo del Ecuador (MINTUR) define una escala de 4 jerarquías, dotándoles la posibilidad a todos los atractivos naturales de tener un nivel de importancia e interés para los visitantes, motivando a los territorios a incursionar en esta actividad, incentivando a la protección y manejo sostenible de sus recursos y motivando a la generación de iniciativas productivas. 
Las variables que los autores Pérez y Crispín (2005) identifican están enfocadas en: atractivos naturales, su accesibilidad y equipamiento que son requisitos principales para el desarrollo de actividades turísticas; mientras que el MINTUR identifica otras variables: datos generales, calidad y apoyo, que permiten un análisis más profundo para la jerarquización de los atractivos, planteando una correlación con el espacio en el que está presente el atractivo e identificando la riqueza natural, cultural e histórica del mismo, sin embargo la ficha no permite identificar la planta turística con la que cuenta, este es un factor importante ya que un producto turístico debe estar dotado de servicios y actividades para el disfrute de los visitantes, sin embargo la ficha hace referencia a los centros urbanos más cercanos al atractivo, los cuales presentan planta turística apropiada para la visita de los turistas.

El turismo en México recepta turistas a nivel mundial, por lo que fichas de evolución del potencial turístico identifican la existencia de accesibilidad a estos recursos por medio de transporte terrestre, marítimo y aéreo, únicamente para los visitantes (Pérez \& Crispín, 2005), mientras que en el caso de Ecuador se enfocan en responder e identificar las necesidades con respecto a infraestructura vial y de acceso, no solo para el disfrute de los visitantes, si no para el aprovechamiento de los pobladores para que tengan la posibilidad de desarrollar actividades productivas, ya que el turismo beneficia a la población o en este caso a la comunidad que lo realiza, sin embargo las fichas han sido creadas con enfoque a la modalidad de turismo comunitario que es la que se desarrolla principalmente en el país ya que los atractivos turísticos están ubicados especialmente en los sectores rurales.

Boullón (2006) menciona que la actividad turística en los países que forman parte de América Latina "tercer mundo" son lugares donde más se violan las declaraciones de protección y conservación, produciendo desastres ecológicos que son frecuentes, sin embargo el estado Ecuatoriano ha desarrollado diversas actividades enfocadas en la protección y conservación de los recursos no solo naturales si no culturales, partiendo de la Constitución Política de la República, título 1, articulo 3.- Deberes primordiales, literal 3.- Defender el patrimonio natural y cultural del país y proteger el medio ambiente, presentándose así como la primera constitución que otorga a la naturaleza derechos y encamina sus acciones a un desarrollo sustentable, equilibrado y equitativo para la colectividad y su entorno. A este enfoque se suma todo el país y aprovecha esta iniciativa creando la imagen turística del país "Ecuador Ama la Vida", con este antecedente el MINTUR como ente rector de la actividad turística, identifica en la ficha de jerarquización el estado de conservación del atractivo y su entorno, para desarrollar actividades que fortalezcan el desarrollo sostenible principalmente con el ambiente. 
Tabla 4. Inventario de atractivos turísticos de la parroquia Guasuntos.

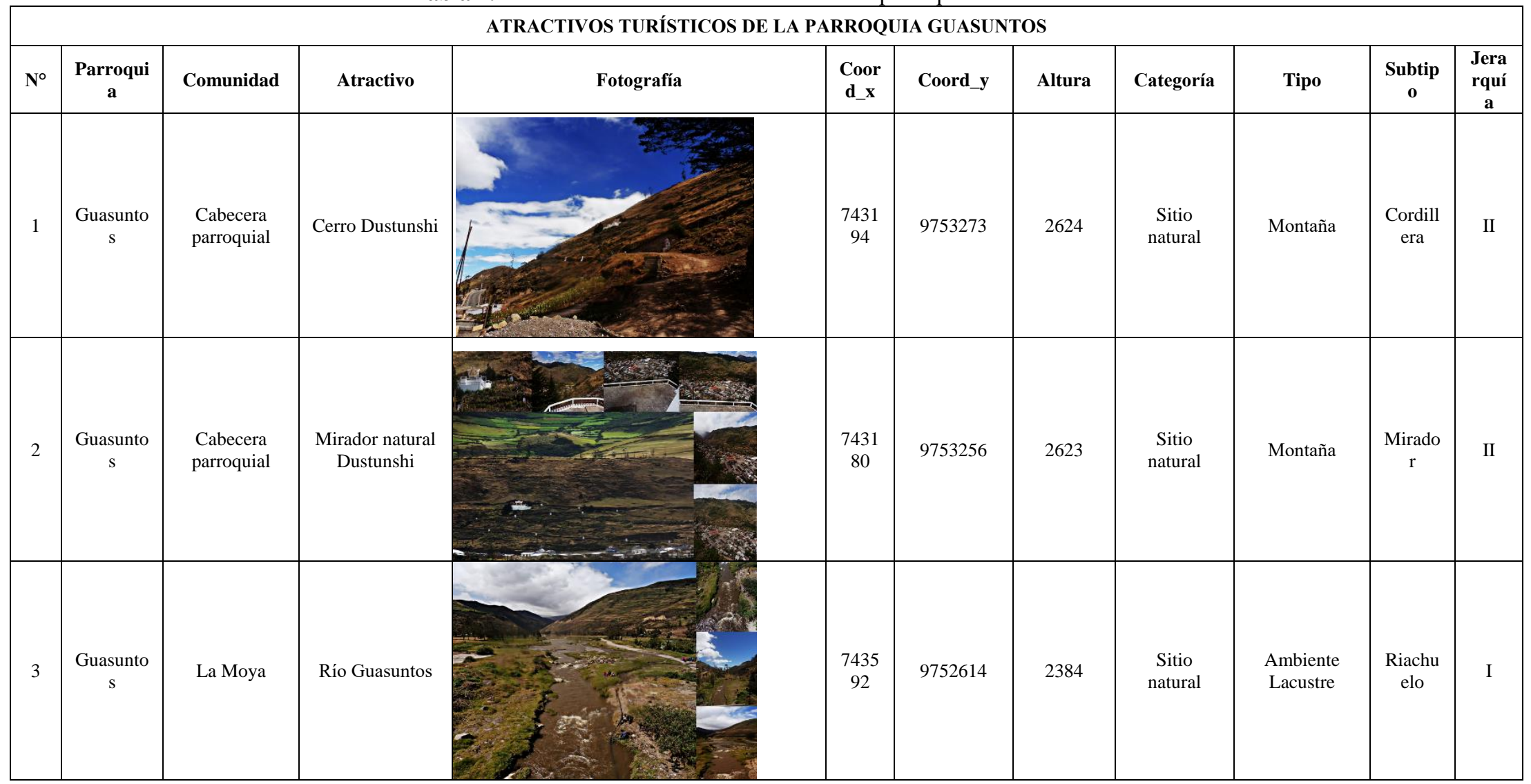




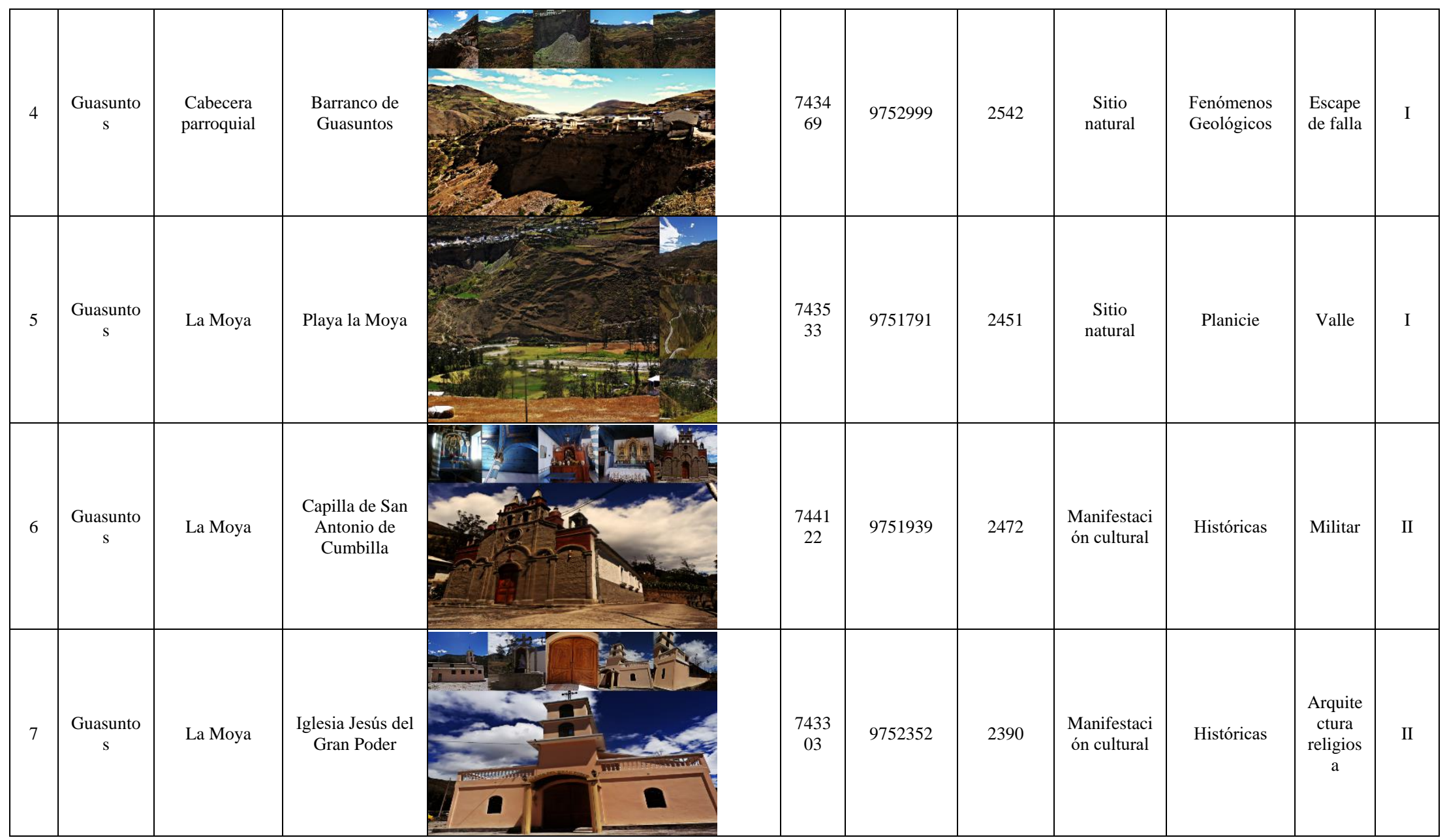




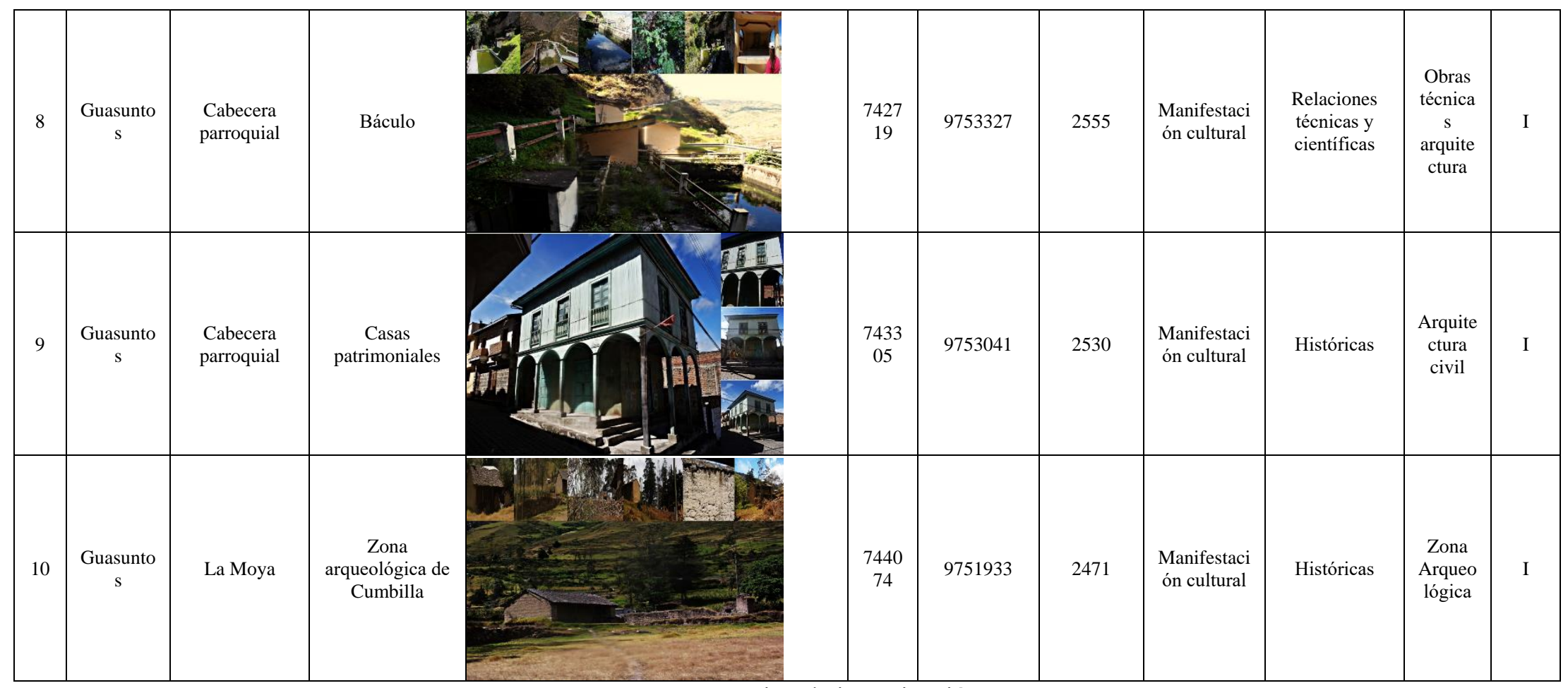

Elaborado por: equipo de investigación

La parroquia rural Guasuntos posee 5 atractivos naturales (Tabla 5), 3 de jerarquía I y 2 de jerarquía II, de igual manera existen 5 atractivos catalogados como manifestaciones culturales, 3 de jerarquía I y 2 de jerarquía II, sin embargo estos espacios tienen la posibilidad de mejorar en indicadores como: estado de conservación del atractivo, estado de conservación del entorno, infraestructura vial y de acceso, infraestructura básica, difusión del atractivo y señalización, no solo para obtener una mayor jerarquización, si no para desarrollar productos turísticos que aporten al desarrollo económico, social, cultural y sostenible del territorio permitiendo así mejorar la calidad de vida de la población que es uno de los objetivos primordiales del

desarrollo 
Tabla 5. Resumen de la valoración y jerarquización de los atractivos turísticos de la parroquia Guasuntos.

\begin{tabular}{|c|c|c|c|}
\hline Criterio & Variable & Cantidad & Porcentaje \\
\hline \multirow{3}{*}{ Categoría } & Sitios naturales & 5 & $50 \%$ \\
\cline { 2 - 4 } & $\begin{array}{c}\text { Manifestaciones } \\
\text { culturales }\end{array}$ & 5 & $50 \%$ \\
\hline \multirow{4}{*}{ Jerarquía } & Total & 10 atractivos & $\mathbf{1 0 0 \%}$ \\
\cline { 2 - 4 } & I & 6 & $60 \%$ \\
\cline { 2 - 4 } & II & 4 & $40 \%$ \\
\cline { 2 - 4 } & III & 0 & $00 \%$ \\
\hline & IV & 0 & $00 \%$ \\
\hline
\end{tabular}

Elaborado por: equipo de investigación

\section{Guasuntos: Principales Atractivos Turísticos}

En el mapa de localización física de los atractivos (mapa 2) se identifican las comunidades, ríos, carreteras y caminos que unen a los atractivos turísticos entre sí, y se ubican los atractivos turísticos en el territorio por medio de símbolos, como una herramienta para la planificación de la actividad turística en la comunidad.

Mapa 2. Atractivos naturales y culturales con potencial turístico de la parroquia Guasuntos

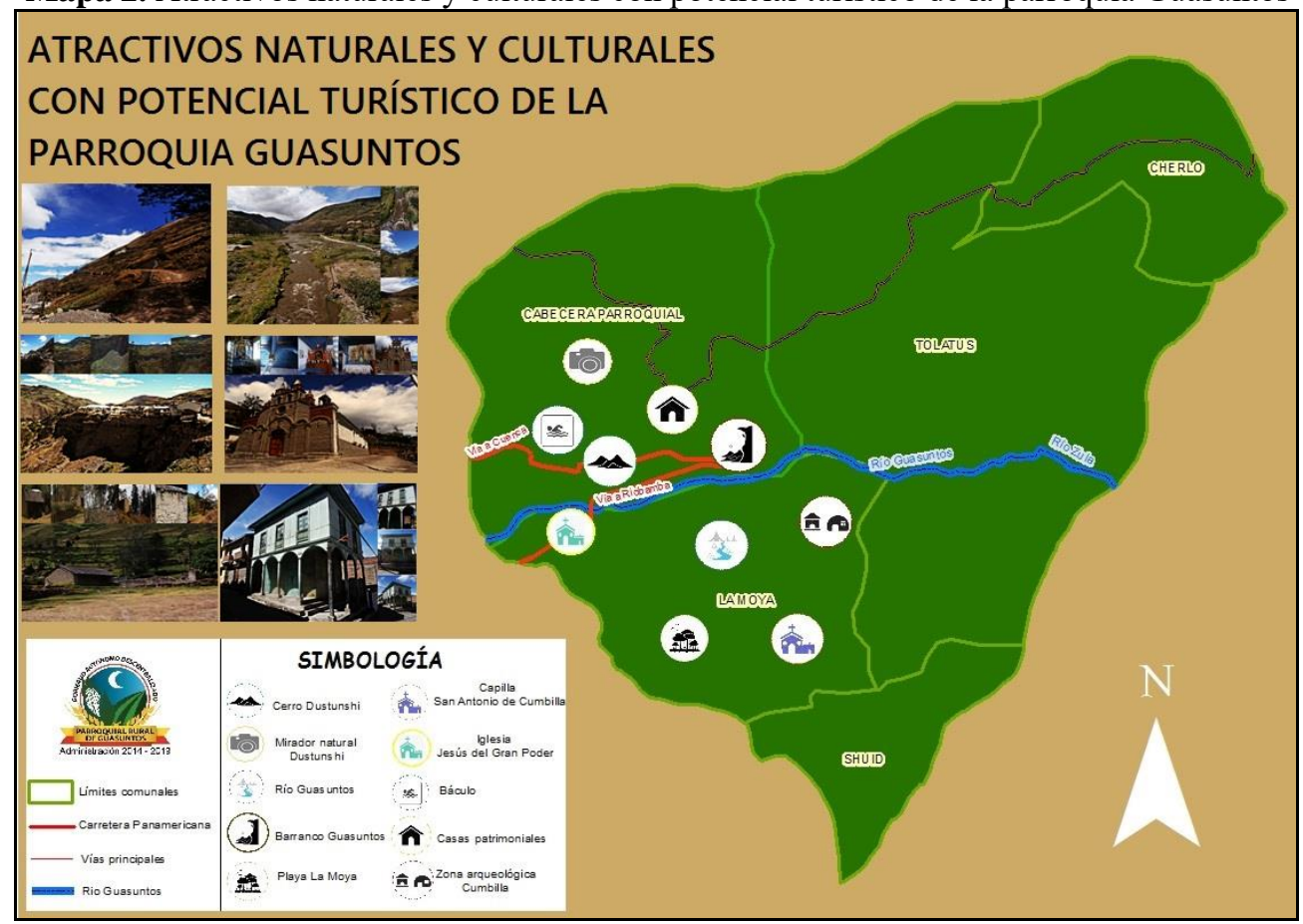

Elaborado por: equipo de investigación 


\section{Caracterización de la Demanda}

Boullón (2006) menciona que el hecho de que alguien esporádicamente viaje a un lugar no es suficiente razón como para decir que éste funciona turísticamente. Por lo tanto el espacio turístico puede ser real o potencial, sin embargo el hecho que de que un espacio motive la visitación es una razón importante y estratégica para la generación de productos turísticos que aumenten la incidencia de estas visitas, para esto es necesario caracterizar la demanda (Tabla 6) que permite conocer los gustos y preferencias de los visitantes.

Tabla 6. Caracterización de la demanda

\begin{tabular}{|c|l|l|}
\hline Preguntas & \multicolumn{1}{|c|}{ Turistas Nacionales } & \multicolumn{1}{|c|}{ Turista Extranjero: } \\
\hline $\begin{array}{c}\text { Conocimiento de la } \\
\text { parroquia Guasuntos de } \\
\text { los potenciales clientes. }\end{array}$ & $64 \%$ si & $09 \%$ si \\
& $36 \%$ no & $91 \%$ no \\
\hline Aceptación del producto & $90 \%$ si & $66 \%$ si \\
de los potenciales clientes. & $10 \%$ no & $34 \%$ no \\
\hline & $14 \%$ fotografía turística & $09 \%$ fotografía turística \\
& $18 \%$ cabalgata & $19 \%$ cabalgata \\
Preferencia por & $17 \%$ ciclismo & $16 \%$ ciclismo \\
actividades turísticas a & $18 \%$ agroturismo & $16 \%$ agroturismo \\
realizar de los potenciales & $04 \%$ caminatas & $06 \%$ caminatas \\
clientes. & $16 \%$ recorrido en granjas & $19 \%$ recorrido en granjas \\
& $02 \%$ convivencia & $06 \%$ convivencia \\
& comunitaria & $09 \%$ turismo cultural \\
\hline $\begin{array}{c}\text { Gasto por día en } \\
\text { actividades turísticas de los }\end{array}$ & $33 \%$ - $\$ 20$ a $\$ 50$ & $22 \%$ - $\$ 20$ a $\$ 50$ \\
potenciales clientes. & $19 \%$ más de $\$ 70$ & $59 \%-\$ 51$ a $\$ 70$ \\
\hline
\end{tabular}

Elaborado por: equipo de investigación

Las preguntas que se plantearon para caracterizar la demanda fueron tomadas como variables estratégicas para la construcción de productos turísticos, el territorio recibe turistas nacionales e internacionales, sin embargo el $64 \%$ de los turistas nacionales conoce la parroquia mientras que de los turistas internacionales solo el 9\% la conoce, esta variable permite identificar que el principal mercado estará enfocado a los turistas nacionales.

La siguiente variable permitió identificar el nivel de aceptación del producto, en el caso de turistas nacionales el $90 \%$ acepta la implementación y de los turistas internacionales el 66\%; esta variable se presenta como estratégica aunque el $91 \%$ de los turistas internacionales que no conoce la parroquia les gustaría que se realice esta implementación identificando al mercado internacional como una posibilidad para la generación de productos.

En la variable de preferencia por actividades a realizar, los turistas nacionales prefieren realizar cabalgata $18 \%$, ciclismo $17 \%$, agroturismo $18 \%$, recorrido en granjas $16 \%$, estas actividades guardan similitud con la 
preferencia de los turistas internacionales el 19\% cabalgata, 16\% ciclismo, $16 \%$ agroturismo y $19 \%$ recorrido en granjas; esta variable permitió determinar que el nivel de efectividad de las actividades a desarrollarse en el producto turístico es alta.

Finalmente, en la variable de gasto por día en actividades, los turistas nacionales están dispuestos a realizar un gasto entre $\$ 51.00$ y $\$ 70.00$ en un $48 \%$, sin embargo en los turistas internacionales el porcentaje es más alto, con $59 \%$ dispuestos a pagar entre $\$ 51.00$ y $\$ 70.00$.

El análisis de las variables permitió determinar que el mayor mercado a enfocar el producto es el de turistas nacionales y que existe una posibilidad de mercado internacional.

En la parroquia Guasuntos, la Playa de la comunidad la Moya es el atractivo que recibe la mayor cantidad de visitantes, su ubicación es estratégica y cuenta con espacios naturales y paisajísticos, tiene una extensión de $100.220 \mathrm{~m}^{2}$, siendo un escenario adecuado para el diseño de un producto turístico enfocado en el esparcimiento y recreación para el público. La comunidad ha identificado el potencial turístico y la aceptación del producto, se desarrollaron varios talleres participativos para captar las ideas generadas por los pobladores de la comunidad, a partir de lo cual se identificó la propuesta para la creación de un complejo turístico (Figura 1 y 2) aprovechando el espacio dispuesto en la Playa de la comunidad la Moya para integrar los gustos y preferencias a partir de la caracterización de la demanda y las iniciativas productivas que la población propone.

Figura 1. Propuesta de diseño del complejo turístico

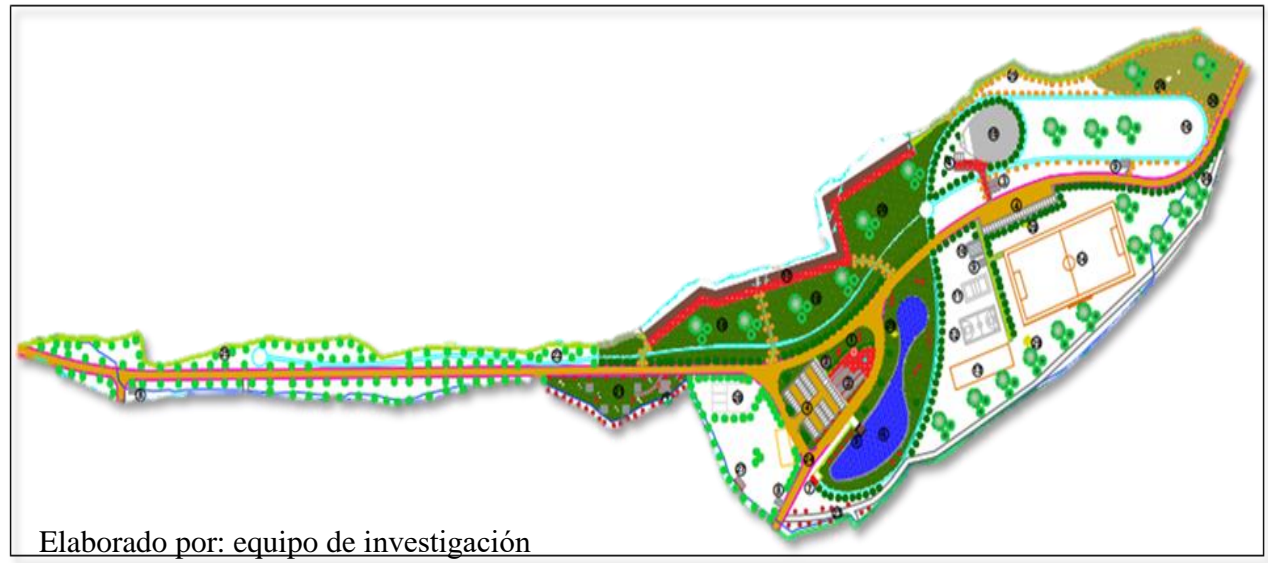

El GADPR de Guasuntos tiene la predisposición para crear el producto turístico, sin embargo la inversión necesaria asciende a un monto de 1958616.38 USD, integrados por activos fijos, activos diferidos y capital de trabajo (Tabla 7). 
Dado que el GADPR de Guasuntos no tiene la capacidad de inversión para el producto turístico, ya que el presupuesto disponible es de 21243503.45 USD, el cual debe ser distribuido en varios ejes de atención: $10 \%$ para las personas vulnerables (niños, ancianos y discapacitados), 30\% gasto corriente (sueldos y salarios de los servidores públicos del GADPR de Guasuntos) y el $60 \%$ inversión en obras públicas.

Sin embargo, una de las competencias del GADPR de Guasuntos es la gestión de la cooperación internacional amparada en el artículo 131 del COOTAD (podrán gestionar la obtención de recursos de la cooperación internacional y asistencia técnica para el cumplimiento de sus competencias propias en el marco de los objetivos de los planes de desarrollo y los principios de equidad, solidaridad, interculturalidad, subsidiariedad, oportunidad y permanencia se mantendrá un registro en el sistema nacional de cooperación internacional). En base a lo mencionado el GADPR está en la capacidad de identificar organizaciones internacionales que tengan la capacidad de inversión para el proyecto, y en el Ecuador se han desarrollado ya varios proyectos en los cuales han intervenido organismos no gubernamentales, como es el caso del "Proyecto de Turismo Rural Comunitario Pistishí - Nariz del Diablo" ubicado en el cantón Alausí, provincia de Chimborazo, desarrollado con el financiamiento proveniente de cooperación internacional canalizado por las fundaciones: Maquita Cushunchic (MCCH) y AVANTI, entidades gubernamentales: GAD Parroquial de Pistishí, Ministerio de Turismo (MINTUR), la Empresa de Ferrocarriles del Ecuador (EFE), el Municipio de Alausí y GAD Provincial de Chimborazo, con los que se desarrolló una propuesta y consecuentemente la ejecución del proyecto de turismo comunitario en las comunidades de Tolte y Achaisí, sector Nariz del Diablo en la parroquia Pistishí (Castillo \& Quevedo, 2016), siendo un proyecto exitoso a nivel nacional y pionero en la demostración de que el turismo comunitario puede ser una alternativa de desarrollo para los territorios rurales de la nación. Este caso, es además tomado como un referente para nuevas iniciativas de proyectos productivos y turísticos.

Tabla 7. Inversión de proyecto

\begin{tabular}{|l|r|}
\hline \multicolumn{2}{|c|}{ INVERSIONES } \\
\hline \multicolumn{1}{|c|}{ DENOMINACIÓN } \\
\hline \multicolumn{1}{|c|}{ Activos fijos } & \multicolumn{1}{c|}{ INVERSIÓN } \\
\hline Maquinarias y equipos & 1885525.06 \\
\hline Muebles y enseres & 11250.00 \\
\hline Equipos de computo & 620.00 \\
\hline Vehículos & 1050.00 \\
\hline Construcciones y edificaciones & 0.00 \\
\hline Terrenos & 1871791.76 .00 \\
\hline Suministros de oficina & 0.00 \\
\hline
\end{tabular}




\begin{tabular}{|c|c|}
\hline Activos diferidos & 60550.20 \\
\hline Cuñas radiales & 180.00 \\
\hline lona de promoción & 200.00 \\
\hline capacitación al personal & 500.00 \\
\hline Elaboración de estudios de factibilidad & 59670.20 \\
\hline Capital de trabajo & 12541.12 \\
\hline Mano de obra directa & 11701.12 \\
\hline Mano de obra indirecta & 0.00 \\
\hline Sueldos y salarios & 0.00 \\
\hline Servicios básicos & 840.00 \\
\hline TOTAL & 1958616.38 \\
\hline
\end{tabular}

Elaborado por: equipo de investigación

El proyecto requiere una inversión de $\$ 1958616.38$, de los cuales se estima que la junta parroquial de Guasuntos en su fase inicial inviertira un monto de $\$ 60550.20$ que representan los activos diferidos del proyecto (Tabla 7), restando una cantidad de $\$ 1898.066 .00$ que necesitan ser financiados, por fundaciones $\mathrm{u}$ organizaciones gubernamentales, no gubernamentales e ingresos que se generarán a partir de las actividades que se desarrollarán por ejemplo el cobro de entradas al parque lineal, pago de arriendo de restaurant, embarque de canoas, baterías sanitarias, caballerizas, concha acústica y parqueaderos.

\section{Conclusion}

La vocación del territorio se convierte en una herramienta de partida para la formulación de proyectos para el desarrollo de productos turísticos sostenibles, que revaloricen la cultura local y mantengan el entorno natural, mismos que deben ser elaborados bajo la concepción del desarrollo humano sostenible buscando el bienestar de la población para mejorar su calidad de vida.

El estudio de la demanda es un punto clave en la formulación del producto turístico con características innovadoras, en función a los gustos y preferencias de los potenciales clientes, en este caso el análisis permitió determinar el mercado a enfocar el producto es el de turistas nacionales y que existe una posibilidad de mercado internacional.

La comunidad cuenta con atractivos naturales y culturales de gran importancia escénica, sin embargo el lugar no puede operar turísticamente, ya que es importante dotarlo de los elementos que facilitan la llegada, desplazamiento y permanencia de los visitantes en el espacio para el aprovechamiento eficiente de sus recursos.

El proyecto del parque lineal Playa la Moya se planteó con el objetivo de brindar una alternativa de distracción recreación familiar a pobladores principalmente de Guasuntos, Alausí, Chunchi, Riobamba, Cuenca, Quito y Guayaquil, así como también a la ciudadanía en general del 
Ecuador, y dinamizar la economía de la comunidad y de la parroquia Guasuntos a través de la generación de fuentes de empleo, finalmente por sus características de concepción el proyecto no recuperará la inversión inicial sin embargo constituye un aporte al desarrollo social, ambiental y económico en la generación de fuentes de empleos directos e indirectos para el territorio, es decir cumple con el principio de la sostenibilidad.

\section{References:}

1. Acevedo, K., Ariza, E., \& Barrios, J. (2010). "Estudio de Factibilidad de un Proyecto". Universidad del Atlántico.

2. Aspas, J. (2000). Los deportes de aventura. Consideraciones jurídicas sobre el turismo activo, Prames, Zaragoza.

3. Benayas, J. (1994). Percepción del paisaje. Naturopa, 75: 11.

4. Bercial, R., \& Timón, D. (2005). "Nuevas tendencias en el desarrollo de destinos turísticos: marcos conceptuales y operativos para su planificación y gestión". Cuadernos de turismo. Cuadernos de turismo(15), 27-44.

5. Blanco, M. (2008). "Guía para la elaboración del plan de desarrollo turístico de un territorio". Disponible en web: www. territorioscentroamericanos. org/turismorural.

6. Boullón, R. (1997). Planificación del espacio turístico. Retrieved from http://felipezunigageotur.blogspot.com/2009/11/glosario-determinos.html

7. Boullón, R. (2006). Espacio turístico y desarrollo sustentable. Aportes y transferencias, 10(2), 17-24.

8. Burgos, D., \& Cardona, M. (2014). "Turismo comunitario, como estrategia para el empoderamiento comunitario en las localidades de Ciudad Bolívar, Usme y Sumapaz, zona rural”. Bogotá DC. Revista Teoría y Praxis Investigativa, 9(2), 94-114.

9. Carrasquero, D. (2004). Estudio de mercado y de factibilidad de producto.

Retrieved from http://www.gestiopolis.com/recursos3/docs/mar/estmktpref.htm

10. Castillo \& Quevedo (2016). "Evaluación del desarrollo en los proyectos de turismo comunitario". Estudio de caso "Proyecto de Turismo Rural Comunitario Pistishí - Nariz del Diablo."

11. Castro, R. (2010). Elementos de turismo teoría, clasificación y actividades. San José-Costa Rica

12. CODESPA. (2011). "Modelo de Gestión del Turismo Rural Comunitario: Una Experiencia Regional Andina”. Lima - Perú [11]. Retrieved from http://www.bibliotecavirtual.info/wpcontent/uploads/2013/02/modelo-gestion-turismo-rural-comunitariocodespa.pdf 
13. De Blas, X., Pardellas, F., \& Padín, C. (2004). "Una propuesta de turismo sostenible para el municipio de Caldas de Reis (Pontevedra)". Cuadernos de turismo(13), 107-126.

14. Geo Argentina (2004). Perspectivas del medioambiente de la Argentina. Buenos Aires: pnuma, Secretaría de Ambiente y Desarrollo sustentable.

15. Gil, A. (2003). La evaluación del medio para la práctica de actividades turístico-deportivas en la naturaleza. Cuadernos de turismo, no 12, p. 131-150.

16. Jiménez, G. (1986). El sistema turístico. Retrieved from http://www.boletin-turistico.com/diccionarioturismo/

17. Meethan, K. (2005). "Tourism in global society. Place, culture, consumption". Relaciones: Estudios de historia y sociedad. New York: Palgrave, 26(103), 270-277.

18. MCPEYC. (2014). Ministerio Coordinador de Producción, Empleo y Competitividad. "Cambio de la matriz productiva".

19. MINTUR. (2009). Ministerio de Turismo. (Online).www.turismo.gob. ec http://www.usfq.edu.ec/publicaciones/polemika/Documents/polemika 005/polemika005_006_articulo003.pdf

20. Monreal, P. (2002). "El turismo como industria cultural. Hacia una nueva estrategia de desarrollo turístico en América Latina y el Caribe". Patrimonio Cultural y Turismo. Cuadernos, 3, 213-236.

21. Pérez, Ó. R., \& Crispín, Á. S. (2005). Metodología para determinar el potencial de los recursos turísticos naturales en el estado de Oaxaca, México. Cuadernos de turismo, (16), 153-174.

22. Salinas, E. \& Quintela, J. (2001). Paisajes y Ordenamiento Territorial: Obtención del mapa de paisajes del estado de Hidalgo en México a escala media con el apoyo de los SIGRevista de Investigación del Bajo Segura, 2, 517-527 [ Links ].

23. Santana, A. (2003). "Turismo cultural, culturas turísticas. Horizontes antropológicos" [31-57]. Retrieved from http://www.scielo.br/scielo.php?pid=S0104-

$71832003000200003 \&$ script=sci_arttext

24. SENPLADES. (2013). "Secretaría Nacional de Planificación y Desarrollo - Plan Nacional de Desarrollo / Plan Nacional para el Buen Vivir". 2013-2017.: Resolución 2 Registro Oficial Suplemento 78 de 11-sep-2013.

25. Sharpley, R. (2000). "Tourism and sustainable development: Exploring the theoretical divide". Journal of Sustainable tourism, 8(1), 1-19. 
26. Valencia, J. (2012). El sistema turístico. Retrieved from http://www.boletin-turistico.com/diccionarioturismo/ 